\title{
Integrative genomic analysis of interleukin-36RN and its prognostic value in cancer
}

\author{
ZHILEI LV*, JINSHUO FAN*, XIUXIU ZHANG, QI HUANG, JIELI HAN, \\ FENG WU, GUORONG HU, MENGFEI GUO and YANG JIN
}

\begin{abstract}
Department of Respiratory and Critical Care Medicine, Key Laboratory of Pulmonary Diseases of the Ministry of Health, Union Hospital, Tongji Medical College, Huazhong University of Science and Technology, Wuhan, Hubei 430022, P.R. China
\end{abstract}

Received January 18, 2015; Accepted October 28, 2015

DOI: $10.3892 / \mathrm{mmr} .2015 .4667$

\begin{abstract}
Interleukin (IL)-36RN, previously known as IL1-F5 and IL-1 $\delta$, shares a $360-\mathrm{kb}$ region of chromosome $2 \mathrm{q} 13$ with members of IL-1 systems. IL-36RN encodes an anti-inflammatory cytokine, IL-36 receptor antagonist (IL-36Ra). In spite of IL-36Ra showing the highest homology to IL-1 receptor (IL-1R) antagonist, it differs from the latter in aspects including its binding to IL-IRrp2 but not to IL-1R1. IL-36RN is mainly expressed in epithelial cells and has important roles in inflammatory diseases. In the present study, IL-36RN was identified in the genomes of 27 species, including human, chimpanzee, mouse, horse and dolphin. Human IL-36RN was mainly expressed in the eye, head and neck, fetal heart, lung, testis, cervix and placenta; furthermore, it was highly expressed in bladder and parathyroid tumors. Furthermore, a total of 30 single nucleotide polymorphisms causing missense mutations were determined, which are considered to be the causes of various diseases, such as generalized pustular psoriasis. In addition, the link between IL-36RN and the prognosis of certain cancer types was revealed through meta-analysis. Tumor-associated transcriptional factors c-Fos, activator protein-1, c-Jun and nuclear factor $\kappa \mathrm{B}$ were found to bind to the upstream region in the IL-36RN gene. This may indicate that IL-36RN is involved in tumorigenesis and tumor progression through the regulation of tumor-associated transcriptional factors. The present study identified IL-36RN in various species and investigated the associations between IL-36RN and cancer prognosis, which would determine
\end{abstract}

Correspondence to: Dr Yang Jin, Department of Respiratory and Critical Care Medicine, Key Laboratory of Pulmonary Diseases of the Ministry of Health, Union Hospital, Tongji Medical College, Huazhong University of Science and Technology, 1277 Jiefang Avenue, Wuhan, Hubei 430022, P.R. China

E-mail:whuhjy@126.com

*Contributed equally

Key words: interleukin-36RN, comparative genomics, cancer, prognosis, meta-analysis whether IL-36RN drove the evolution of the various species with regard to tumorigenesis.

\section{Introduction}

Interleukin (IL)-36RN was first discovered as an IL-1 family

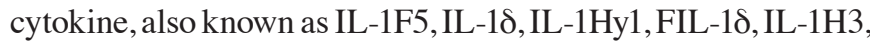
IL-1RP3 and IL-1L1 (1,2), which is, together with classic IL-1 members, IL-37 and other IL-36 cytokines (IL-36 $\alpha$, IL-36 $\beta$ and IL-36 $\gamma$ ) located in a 360-kb region of chromosome 2 q13 (3). IL-36RN was identified to encode anti-inflammatory cytokine IL-36Ra, which is $52 \%$ homologous to the IL receptor antagonist (IL-1Ra) (4). IL-36Ra binds to IL-1Rrp2 and inhibits IL-36 $\alpha$, IL-36 $\beta$ and IL-36 $\gamma$ in similar manner to IL-1Ra inhibiting IL-1 $\alpha$ and IL-1 $\beta$ (5). In spite of its similar functions to those of IL-1Ra, IL-36Ra itself can induce IL-4 expression in glial cells, while IL-4 is indispensable for the anti-inflammatory activities of IL-36Ra in the brain; however, IL-1Ra has not been found to induce any cytokines (6). To facilitate functional investigations, IL-36 cytokines, including IL-36Ra, were re-named in 2010 with the aim to distinguish them from the IL-1 cytokines (2).

With regard the functions of IL-36, the perturbation of the IL-36 signaling balance contributes to the pathogenesis of immunological and inflammatory diseases (7). The balance can be disrupted by aberrant expression of either agonists or antagonists of IL-36 signaling. The IL-36R signaling agonists IL-36 $\alpha$, $-\beta$ and $-\gamma$ are highly expressed in several inflammatory diseases, including chronic obstructive pulmonary disease (8), asthma (9), obesity (10), ankylosing spondylitis (11), rheumatoid arthritis (12) and allergic contact dermatitis (13), and have a significant role in these diseases. As an antagonist of IL-36 signaling, IL-36Ra is also implicated in the pathogenesis of immunological and inflammatory conditions. IL-36Ra expression is associated with Kindler syndrome (14), brain micromotion (15) and psoriasis (16). It was recently shown that mutations of IL36RN are closely associated with a serious disease called general pustular psoriasis (GPP) (17-20). Single-nucleotide polymorphisms (SNPs) in the IL-36RN gene can lead to induction of a premature stop-codon, frame-shift mutation or an amino acid substitution, resulting in a misfolded IL-36Ra protein that is less stable and poorly expressed $(17,18,20)$. However, the roles of IL-36Ra in inflammation-associated tumors have not been clearly elucidated, while IL-36 signaling has been implicated 

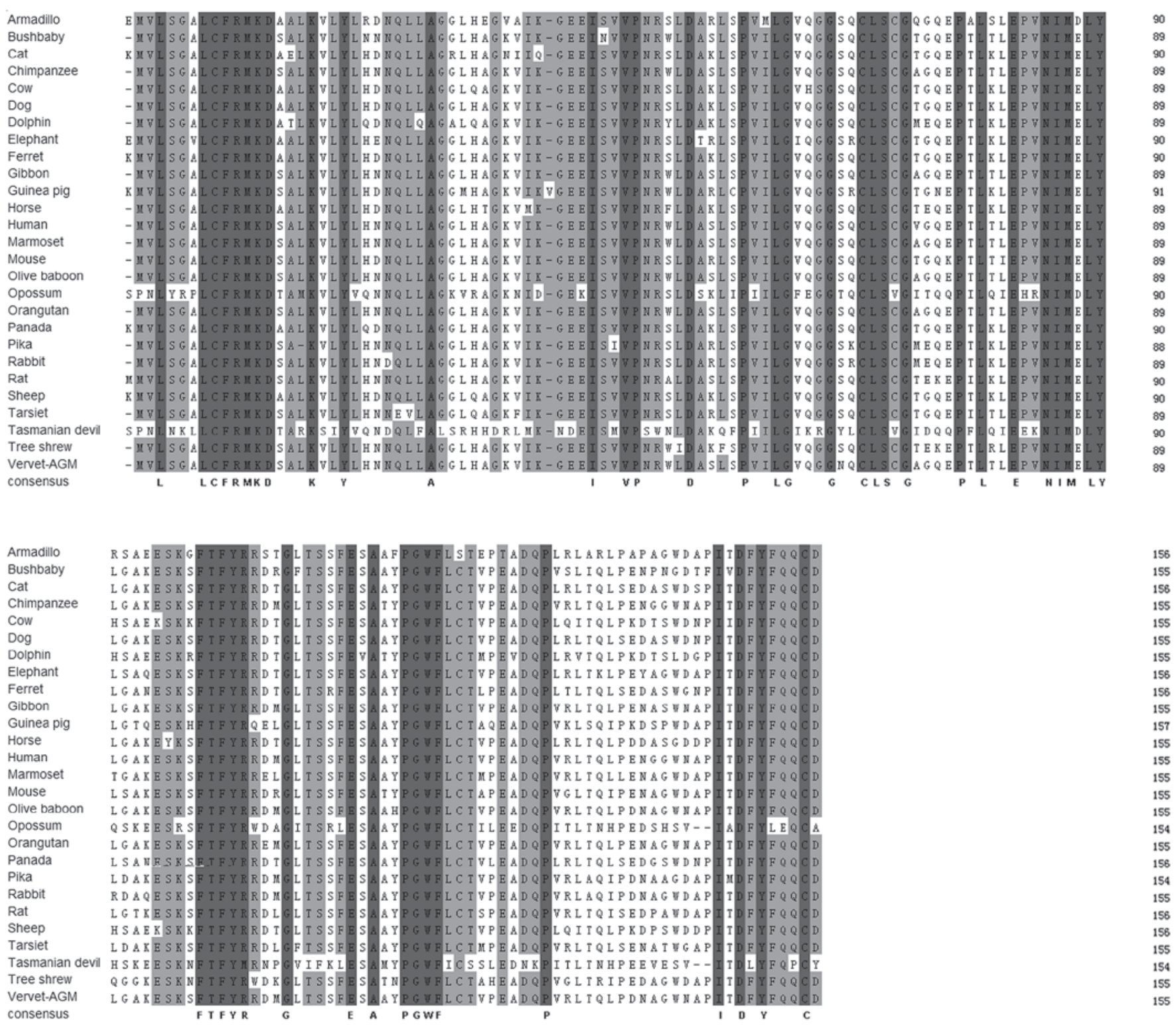

Figure 1. Alignments of amino acid sequence of the identified IL-36RN. The complete IL-36RN genes were identified in 27 mammalian genomes. AGM, African green monkey.

in inflammatory diseases; therefore, an integrative analysis of IL-36RN and its prognostic value in cancer is required.

The present study assessed the IL-36RN gene in a wide range of genomes using integrative genomic analyses. Subsequently, functionally relevant SNP analysis and comparative proteomic analysis of IL-36RN were conducted. The conserved transcription-factor binding sites within the upstream region of IL-36RN as well as the prognostic value of IL-36RN in cancer were investigated.

\section{Materials and methods}

Identification of the IL-36RN gene in vertebrate genomes and integrative genomic analyses. The nucleotide and amino acid sequences of IL-36RN were obtained from the Ensembl database (www.ensembl.org), based on orthologous and paralogous relationships. The IL-36RN gene sequences subjected to analysis with the Basic Local Alignment Search Tool (BLAST;
http://blast.ncbi.nlm.nih.gov/Blast.cgi) against the GenBank database (http://www.ncbi.nlm.nih.gov/genbank/) to confirm that the best hits were the IL36RN genes for the selected species. Conserved transcription-factor binding sites within promoter regions of the human IL-36RN gene were obtained from the DECipherment Of DNA Elements proprietary database (http:// www.sabiosciences.com/chipqpcrsearch.php?app=TFBS) of SABiosciences (Qiagen, Hilden, Germany), which combines text mining with data from the genome browser of the University of California, Santa Cruz (https://genome.ucsc.edu/).

Comparative proteomic analysis of the IL-36RN protein. The ClustalW software implemented in MEGA 5.05 (http:// www.megasoftware.net/) was used to align the protein-coding sequences of IL-36RN. A maximum likelihood tree of IL-36RN amino acid sequences was constructed using MEGA 5.05 with the Kimura 2-parameter model (21). For the relative support of the internal node, bootstrap analysis was 


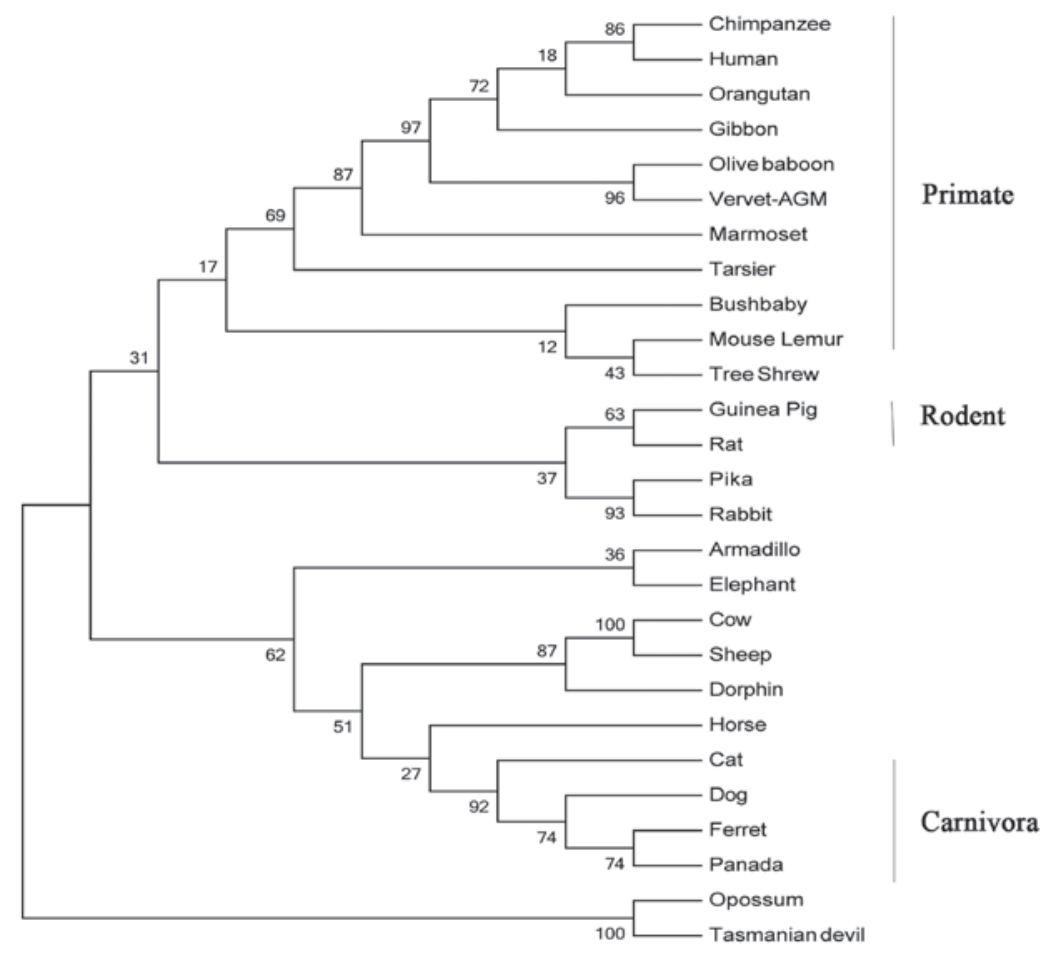

Figure 2. Phylogenetic analysis of IL-36RN. The phylogenetic tree was constructed according to the protein coding sequences using the maximum likelihood and neighbor-joining methods. The IL-36RN gene from primate lineage was clustered into a species-specific group. IL-36RN, interleukin-36RN.

performed with 1,000 replications for ML reconstructions. The positive selection of IL-36RN during evolution (22) was analyzed using the program CodeML implemented in the PAML4.7 software package (http://abacus.gene.ucl.ac.uk/software/paml.html). Codon subsitution models M0 (one ratio), M1a (NearlyNeutral), M2a (PositveSelection), M7 ( $\beta$ ) and M8 $(\beta$ and $\omega)$ were used. The site-specific model was generated using likelihood ratio tests to compare the models as previously described (23).

In silico expression analyses of the human IL-36RN gene. The expression profiles of normal human tissues were acquired from GeneAnnot (http://genecards.weizmann.ac.il/geneannot/ index.shtml) and ArrayExpress (https://www.ebi.ac.uk/arrayexpress/). Using the human IL-36RN gene (GenBank ID, NC_000002.12) as a query sequence, expressed sequence tags (ESTs) derived from the human IL-36RN gene were identified by BLAST as described previously (24). Virtual northern blot analysis was also performed by searching the uniGene database of the National Center of Biotechnology Information (NCBI) (http://www.ncbi.nlm.nih.gov/unigene). In addition, protein expression profiles of IL-36RN were obtained from the Systematic Protein Investigative Research Environment (25) and the Model Organism Protein Expression Database (26).

Evaluation of functionally relevant SNPs of the human IL-36RN gene and identification of somatic mutations in human cancer. Ensembl (http://www.ensembl.org/index.html) and the NCBI's Database of SNPs (http://www.ncbi.nlm.nih. gov/snp/) were used to obtain functionally relevant SNPs of the human IL-36RN gene as previously described $(24,27,28)$. The SNPs that could disrupt exonic splicing enhancer (ESE)/exonic splicing silencer (ESS) motifs or cause a missense mutation were identified. Somatic mutations of the IL-36RN gene were identified in human cancer types from the Catalogue Of Somatic Mutations In Cancer (COSMIC) database (http://cancer.sanger. ac.uk/cosmic/), which mines complete cancer genomes (29).

Meta-analysis of the prognostic value of the IL-36RN gene in cancer. The PrognoScan database (http://www.prognoscan. org/) (30) contains a large collection of publicly available cancer microarray datasets with clinical annotation, enabling it to also be used as an efficient tool for assessing the association between gene expression and cancer prognosis. During gene analysis, PrognoScan employed the minimum P-value approach for grouping patients for survival analysis. Data was collected for further analysis by searching the IL-36RN gene as a query in PrognoScan.

\section{Results}

Comparative proteomic analysis of the IL-36RN protein. All the IL-36RN gene and protein sequences were collected from the Ensembl database and then confirmed by BLAST. The complete IL-36RN genes were identified in human, chimpanzee, gibbon, orangutan, olive baboon, vervet-African green monkey, marmoset, bush baby, tarsier, rabbit, pika, rat, mouse, elephant, cat, dog, panda, ferret, horse, cow, dolphin, guinea pig, sheep, opossum, tasmanian devil, armadillo and tree shrew genomes. The sequence and structural alignment of IL-36RN is illustrated in Fig. 1. Refined phylogentic trees generated using the identified IL-36RN protein amino acid sequences by ML and neighbor-joining (NJ) methods were almost identical; therefore, only the results of the ML method are presented (Fig. 2). It appeared that the IL-36RN protein from the primate lineage forms a species-specific cluster. Site-specific analysis for posi- 
Table I. Exon and intron lengths of IL-36RN.

\begin{tabular}{|c|c|c|c|c|c|c|c|c|c|c|c|c|}
\hline \multirow[b]{2}{*}{ Species } & \multicolumn{12}{|c|}{ Length (bp) } \\
\hline & $\begin{array}{c}\text { Exon } \\
1\end{array}$ & $\begin{array}{c}\text { Intron } \\
1\end{array}$ & $\begin{array}{c}\text { Exon } \\
2\end{array}$ & $\begin{array}{c}\text { Intron } \\
2\end{array}$ & $\begin{array}{c}\text { Exon } \\
3\end{array}$ & $\begin{array}{c}\text { Intron } \\
3\end{array}$ & $\begin{array}{c}\text { Exon } \\
4\end{array}$ & $\begin{array}{c}\text { Intron } \\
4\end{array}$ & $\begin{array}{c}\text { Exon } \\
5\end{array}$ & $\begin{array}{l}\text { Intron } \\
5\end{array}$ & $\begin{array}{c}\text { Exon } \\
6\end{array}$ & $\begin{array}{l}\text { Total } \\
\text { exons }\end{array}$ \\
\hline Armadillo & 32 & 734 & 86 & 820 & 128 & 756 & 225 & - & - & - & - & 471 \\
\hline Bushbaby & 29 & 1343 & 86 & 1280 & 128 & 199 & 225 & - & - & - & - & 468 \\
\hline Cat & 32 & 1334 & 86 & 1036 & 128 & 202 & 225 & - & - & - & - & 471 \\
\hline Chimpanzee & 29 & 1384 & 86 & 1187 & 128 & 201 & 225 & - & - & - & - & 468 \\
\hline Cow & 29 & 1334 & 86 & 1014 & 128 & 171 & 225 & - & - & - & - & 468 \\
\hline Dog & 29 & 1553 & 86 & 1058 & 128 & 194 & 225 & - & - & - & - & 468 \\
\hline Dolphin & 29 & 1518 & 86 & 998 & 128 & 171 & 225 & - & - & - & - & 468 \\
\hline Elephant & 32 & 1510 & 86 & 976 & 128 & 220 & 225 & - & - & - & - & 471 \\
\hline Ferret & 32 & 1539 & 86 & 1032 & 128 & 175 & 225 & - & - & - & - & 471 \\
\hline Gibbon & 29 & 1382 & 86 & 1182 & 128 & 201 & 225 & - & - & - & - & 468 \\
\hline Guinea Pig & 32 & 1650 & 86 & 1282 & 131 & 203 & 225 & - & - & - & - & 474 \\
\hline Horse & 29 & 1369 & 86 & 1050 & 128 & 197 & 225 & - & - & - & - & 468 \\
\hline Human & 29 & 1384 & 86 & 1186 & 128 & 201 & 225 & - & - & & - & 468 \\
\hline Marmoset & 29 & 1380 & 86 & 1187 & 128 & 201 & 225 & - & - & - & - & 468 \\
\hline Mouse Lemur & 29 & 1353 & 86 & 1264 & 128 & 200 & 225 & - & - & - & - & 468 \\
\hline Olive baboon & 29 & 1385 & 86 & 1197 & 128 & 200 & 222 & - & - & - & - & 465 \\
\hline Opossum & 118 & 1450 & 128 & 348 & 219 & - & - & - & - & - & - & 465 \\
\hline Orangutan & 29 & 1384 & 86 & 1184 & 128 & 201 & 225 & - & - & - & - & 468 \\
\hline Panda & 32 & 1579 & 86 & 1055 & 128 & 201 & 225 & - & - & - & - & 471 \\
\hline Pika & 29 & 797 & 16 & 3 & 25 & 1 & 42 & 1449 & 128 & 161 & 225 & 465 \\
\hline Rabbit & 29 & 1491 & 86 & 1141 & 128 & 198 & 225 & - & - & - & - & 468 \\
\hline Rat & 32 & 2070 & 86 & 1069 & 128 & 205 & 225 & - & - & - & - & 471 \\
\hline Sheep & 32 & 1332 & 86 & 974 & 128 & 174 & 225 & - & - & - & - & 471 \\
\hline Tarsier & 29 & 1348 & 86 & 1774 & 128 & 218 & 225 & - & - & - & - & 468 \\
\hline Tasmanian devil & 88 & 1432 & 25 & 765 & 5 & 38 & 128 & 293 & 216 & - & - & 462 \\
\hline Tree Shrew & 29 & 1509 & 86 & 1084 & 128 & 237 & 225 & - & - & - & - & 468 \\
\hline $\begin{array}{l}\text { Vervet African } \\
\text { green monkey }\end{array}$ & 29 & 1392 & 86 & 1201 & 128 & 201 & 225 & - & - & - & - & 468 \\
\hline
\end{tabular}

tive selection was performed for primate, rodent, carnivora, mammalian and mammalian excluding primate lineages. By using any of the six models in the IL-36RN proteins, no positive selection site was identified. Instead, purifying selection was observed among the proteins (data not shown). Furthermore, the exon-intron information was collected from the Ensembl database and presented in Table I and Fig. 3. In most of the mammalian genomes, IL-36RN genes had four exons and three introns of similar length. In the primate lineage, IL-36RN genes showed the same exon lengths and numbers with similar exon-intron conservations (Table I). However, IL-36RN genes had six exons and five introns in pikas and only three exons and two introns in opossums. Furthermore, the tasmanian devil was shown to have five exons and four introns in its IL-36RN genes (Table I and Fig. 3).

Expression profile of the human IL-36RN gene. A search of the EST sequence database revealed that the human IL-36RN gene was expressed in the placenta, cervix, lung, head and neck, eye, fetal heart and testis, and furthermore, that it was highly

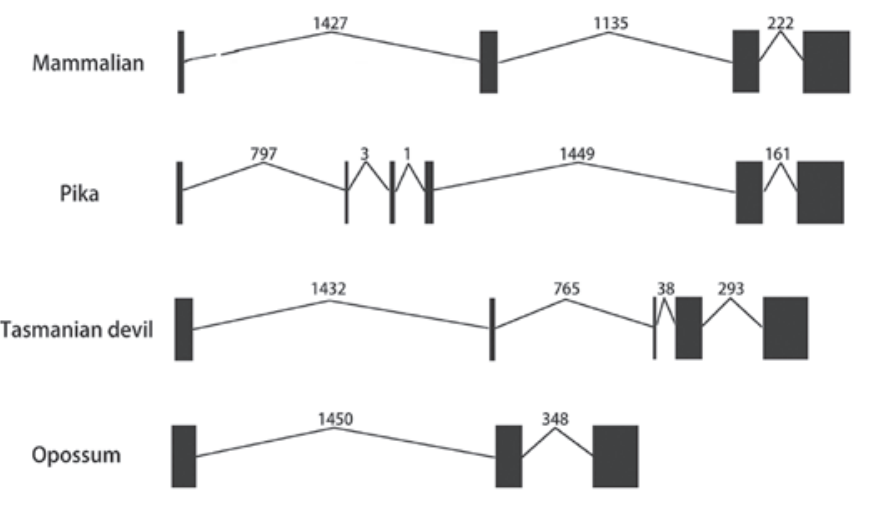

Figure 3. Exon-intron conservation analysis of IL-36RN. In the majority of mammalian genomes, IL-36RN has four exons and three introns of similar length. By contrast, in pikas, IL-36RN has six exons and five introns, while it has five exons and four introns in tasmanian devils, and only three exons and two introns in opossums.

expressed in bladder and parathyroid tumors. Examination of microarray analyses and 'virtual northern blot analysis' 
Table II. Evaluation of the functionally relevant SNP in the human IL-36RN gene.

\begin{tabular}{|c|c|c|c|c|}
\hline SNP ID & Chr 2 position sequence & Sequence & Type & Amino acid change \\
\hline rs143724424 & 113820120 & GCTTC[A/G]AGTCG & Missense & EK \\
\hline rs144478519 & 113820124 & CGAGT[C/T]GGCTG & Missense & SL \\
\hline rs151325121 & 113819727 & CCAAT[C/T]GGTGG & Missense & RW \\
\hline rs387906914 & 113818479 & GCTTC[C/T]AGCTG & Missense & LP \\
\hline rs397514629 & 113820154 & GTGCA[C/G]GGTGC & Missense & TR \\
\hline rs28938777 & 113819725 & CCCCA[A/G]TCGGT & Missense & NS \\
\hline rs77864207 & 113819754 & CСССС[A/G]TCATC & Missense & VI \\
\hline rs139497891 & 113819812 & GGAGC $[\mathrm{C} / \mathrm{T}] \mathrm{GACTC}$ & Missense & PL \\
\hline rs141341649 & 113820136 & $\mathrm{CTACC}[\mathrm{C} / \mathrm{T}] \mathrm{GGGCT}$ & Missense & PL \\
\hline rs144182857 & 113820031 & GCAGC[C/T]AGTGA & Missense & PL \\
\hline rs144420774 & 113820103 & CATGG[C/G]GCTCA & Missense & GA \\
\hline rs145099228 & 113819721 & TGGTC[C/T]CCAAT & Missense & PS \\
\hline rs147389610 & 113818487 & CTGGA[A/G]GGCTG & Missense & GR \\
\hline rs147410197 & 113820087 & ССТTC $[\mathrm{C} / \mathrm{T}] \mathrm{ACCGG}$ & Missense & YH \\
\hline rs187015338 & 113818503 & AGGGA[A/G]GGTCA & Missense & $\mathrm{KR}$ \\
\hline rs199932303 & 113820090 & TCTAC[C/T]GGCGG & Missense & RW \\
\hline rs202059991 & 113820222 & CCCCC $[\mathrm{A} / \mathrm{G}] \mathrm{TCACA}$ & Missense & IV \\
\hline rs369259981 & 113820048 & TGGAG[C/T]TCTAT & Missense & $\mathrm{LF}$ \\
\hline rs371819085 & 113820091 & CTACC $[\mathrm{A} / \mathrm{G}] \mathrm{GCGGG}$ & Missense & RQ \\
\hline rs372880215 & 113819815 & GCCGA[C/T]TCTAA & Missense & TI \\
\hline rs374900764 & 113820247 & GCAGT[A/G]TGACT & Missense & CY \\
\hline rs375207169 & 113820093 & ACCGG $[\mathrm{C} / \mathrm{T}] \mathrm{GGGAC}$ & Missense & RW \\
\hline rs375718709 & 113819793 & TGTCA[C/T]GTGGG & Missense & $\mathrm{CR}$ \\
\hline rs377330697 & 113820172 & CGATC[A/G]GCCTG & Missense & QR \\
\hline rs537559199 & 113820044 & ATCAT[A/G]GAGCT & Missense & MI \\
\hline rs542606182 & 113820094 & CCGGC[A/G]GGACA & Missense & $\mathrm{RQ}$ \\
\hline rs545202535 & 113820237 & TCTAC[A/T]TCCAG & Missense & FI \\
\hline rs545673991 & 113818451 & TGAAG[G/T]TGCTT & Missense & VL \\
\hline rs397514630 & 113817043 & GCTTC[C/T]GGTGA & Nonsense & R-Ter \\
\hline rs368461730 & 113819805 & TGGGG[C/T]AGGAG & Nonsense & Q-Ter \\
\hline
\end{tabular}

Among the 543 available SNPs identified in the human IL-36RN gene, a total of 30 SNPs were functionally relevant, including 28 SNPs causing missense mutations and 2 SNPs causing nonsense mutations. SNP, single nucleotide polymorphism; Chr 2, chromosome 2.

revealed a predominant expression of IL-36RN in cervix, larynx, lung, mouth, muscle, parathyroid, pharynx, placenta and testis. A search of the PrognoScan database revealed that human IL-36RN was also expressed in bladder, blood, brain, breast, colorectal, esophageal, eye, head and neck, lung, ovarian, skin and soft tissue cancer.

Comparative genomics analysis of human IL-36RN. Activator protein 1 (AP-1), c-Fos, c-Jun and nuclear factor (NF)- $\kappa \mathrm{B}$ binding sites were identified within the upstream regions of the transcriptional start site of human IL-36RN.

Functionally relevant SNP evaluation of the human IL-36RN gene and identification of somatic mutations in human cancer. A total of 543 SNPs were identified in the human IL-36RN gene through searching the NCBI SNP and Ensembl databases. Among these SNPs, 30 were functionally relevant, causing missense and nonsense mutations (Table II). As presented in
Table III, by searching the COSMIC database, 31 somatic mutations of the IL-36RN gene were identified in cancer.

Meta-analysis of the prognostic value of IL-36RN gene in cancer. PrognoScan employs the minimum P-value approach for grouping patients with varied cancer types for survival analysis and produces a data-set of results, including cancer type, subtype, endpoint, cohort, contributor, array type, probe ID, number of patients, optimal cut-off point, Pmin and Pcor. For the IL-36RN gene, 7 out of the 84 cancer cases showed correlations between microarray expression in the IL-36RN gene and cancer prognosis (bladder cancer, 1/2; blood cancer, 0/9; brain cancer, $0 / 4$; breast cancer, $1 / 30$; colorectal cancer, $1 / 9$; esophageal cancer, $0 / 1$; eye cancer, $0 / 1$; head and neck cancer, $0 / 1$; lung cancer, 2/15; ovarian cancer, 2/9; skin cancer, 0/1; soft tissue cancer, $0 / 1$ ) with a $5 \%$ significance level (Table IV). Among the two ovarian cancer cases, poor survival in one case was associated with elevated expression of IL-36RN (DUKE-OC), and the 
Table III. Somatic mutations of IL-36RN in tumor tissues.

\begin{tabular}{|c|c|c|c|c|c|}
\hline Position (AA) & Mutation (CDS) & Mutation (amino acid) & Mutation ID (COSM) & Count & Mutation type \\
\hline 3 & c. $9 \mathrm{G}>\mathrm{C}$ & p.L3L & COSM3836628 & 1 & Substitution-coding silent \\
\hline 5 & c. $15 \mathrm{G}>\mathrm{A}$ & p.G5G & COSM3894558 & 1 & Substitution-coding silent \\
\hline 6 & c. $17 \mathrm{C}>\mathrm{T}$ & p.A6V & COSM240220 & 1 & Substitution-missense \\
\hline 10 & c. $28 \mathrm{C}>\mathrm{T}$ & p.R10* & COSM126741 & 1 & Substitution-nonsense \\
\hline 14 & c. $41 \mathrm{C}>\mathrm{T}$ & p.S14L & COSM714706 & 1 & Substitution-missense \\
\hline 15 & c. $44 \mathrm{C}>\mathrm{A}$ & p.A15E & COSM714705 & 1 & Substitution-missense \\
\hline 21 & c. $63 \mathrm{G}>\mathrm{T}$ & p.L21L & COSM381474 & 1 & Substitution-coding silent \\
\hline 29 & c. $85 \mathrm{G}>\mathrm{A}$ & p.G29R & COSM1690946 & 1 & Substitution-missense \\
\hline 34 & c. $102 \mathrm{G}>\mathrm{A}$ & p.G34G & COSM3894559 & 1 & Substitution-coding silent \\
\hline 36 & c. $108 \mathrm{C}>\mathrm{A}$ & p.V36V & COSM169172 & 1 & Substitution-coding silent \\
\hline 37 & c. $110 \mathrm{~T}>\mathrm{C}$ & p.I37T & COSM4084297 & 1 & Substitution-missense \\
\hline 46 & c. $137 \mathrm{C}>\mathrm{T}$ & p.P46L & COSM1690947 & 1 & Substitution-missense \\
\hline 48 & c. $142 \mathrm{C}>\mathrm{T}$ & p.R48W & COSM441016 & 1 & Substitution-missense \\
\hline 54 & c. $160 \mathrm{C}>\mathrm{A}$ & p.L54M & COSM300070 & 1 & Substitution-missense \\
\hline 54 & c. $160 \mathrm{C}>\mathrm{T}$ & p.L54L & COSM3565457 & 1 & Substitution-coding silent \\
\hline 55 & c. $164 \mathrm{C}>\mathrm{T}$ & p.S55F & COSM1690948 & 1 & Substitution-missense \\
\hline 56 & c. $168 \mathrm{C}>\mathrm{A}$ & p.P56P & COSM3565458 & 1 & Substitution-coding silent \\
\hline 71 & c. $212 \mathrm{G}>\mathrm{A}$ & p.G71E & COSM3565459 & 1 & Substitution-missense \\
\hline 73 & c. $218 \mathrm{G}>\mathrm{C}$ & p.G73A & COSM1527707 & 1 & Substitution-missense \\
\hline 86 & c. $258 \mathrm{G}>\mathrm{T}$ & p.M86I & COSM3565460 & 1 & Substitution-missense \\
\hline 92 & c. $275 \mathrm{C}>\mathrm{A}$ & p.A92D & COSM4133012 & 1 & Substitution-missense \\
\hline 95 & c. $284 \mathrm{C}>\mathrm{T}$ & p.S95F & COSM3565461 & 1 & Substitution-missense \\
\hline 97 & c. $290 \mathrm{G}>\mathrm{A}$ & p.S97N & COSM3565462 & 1 & Substitution-missense \\
\hline 106 & c. $317 \mathrm{G}>\mathrm{A}$ & p.G106E & COSM3565463 & 1 & Substitution-missense \\
\hline 112 & c. $334 \mathrm{G}>\mathrm{A}$ & p.E112K & COSM107437 & 1 & Substitution-missense \\
\hline 117 & c. $350 \mathrm{C}>\mathrm{A}$ & p.P117Q & COSM3961011 & 1 & Substitution-missense \\
\hline 126 & c. $378 \mathrm{~A}>\mathrm{G}$ & p.E126E & COSM4084298 & 1 & Substitution-coding silent \\
\hline 136 & c. $406 \mathrm{C}>\mathrm{A}$ & p.L136I & COSM4084299 & 1 & Substitution-missense \\
\hline 137 & c. $411 \mathrm{C}>\mathrm{T}$ & p.P137P & COSM3565464 & 1 & Substitution-coding silent \\
\hline 138 & c. $412 \mathrm{G}>\mathrm{A}$ & p.E138K & COSM275559 & 2 & Substitution-missense \\
\hline 142 & c. $425 \mathrm{G}>\mathrm{T}$ & p.W142L & COSM336664 & 1 & Substitution-missense \\
\hline
\end{tabular}

IL-36RN, interleukin-36RN; COSM, catalogue of somatic mutations; CDS, coding sequences.

other one was associated with decreased expression of IL-36RN (GSE17260). While one case out of nine cases of colorectal cancer showed poor survival associated with decreased expression of IL-36RN, elevated expression of IL-36RN in one case of bladder cancer, one case of breast cancer and two cases of lung cancer was found to be associated with poor survival.

\section{Discussion}

The IL-36RN gene encodes the anti-inflammatory cytokine IL-36Ra, which was previously known as IL-1F5 and later re-defined as a member of the IL-36 cytokine family.

The present study identified IL-36RN from 27 genomes and found that IL-36RN exists in all types of mammals, including primates, rodents and carnivora, as well as elephant, dolphin, sheep, rabbit, horse and armadillo. In the phylogenetic tree, all of the primates were clustered. Furthermore, the exon-intron information indicated that all primates were almost identical with regard to the IL-36RN gene. According to the alignment and phylogenetic tree, IL-36RN was evolutionarily conserved among mammals, indicating a significant biological function of this gene. It is known that IL-36 cytokines are expressed in various tissue types and contribute to inflammatory diseases (7), confirming its biological importance indicated by the present study.

EST sequence analysis revealed that the IL-36RN gene is expressed in the placenta, cervix, lung, head and neck, eye, fetal heart and testis; furthermore, high expression had been detected in bladder and parathyroid tumors. This result implied that IL-36RN is extensively expressed in a large variety of organ and tissue types. A total of 30 SNPs, including 28 SNPs causing missense mutations and 2 SNPs causing nonsense mutations, were analyzed from 543 available SNPs in human IL-36RN genes. Recently, several IL-36RN mutations among the 28 SNPs have been reported as causative genetic defects associated with GPP and related pustular disor- 


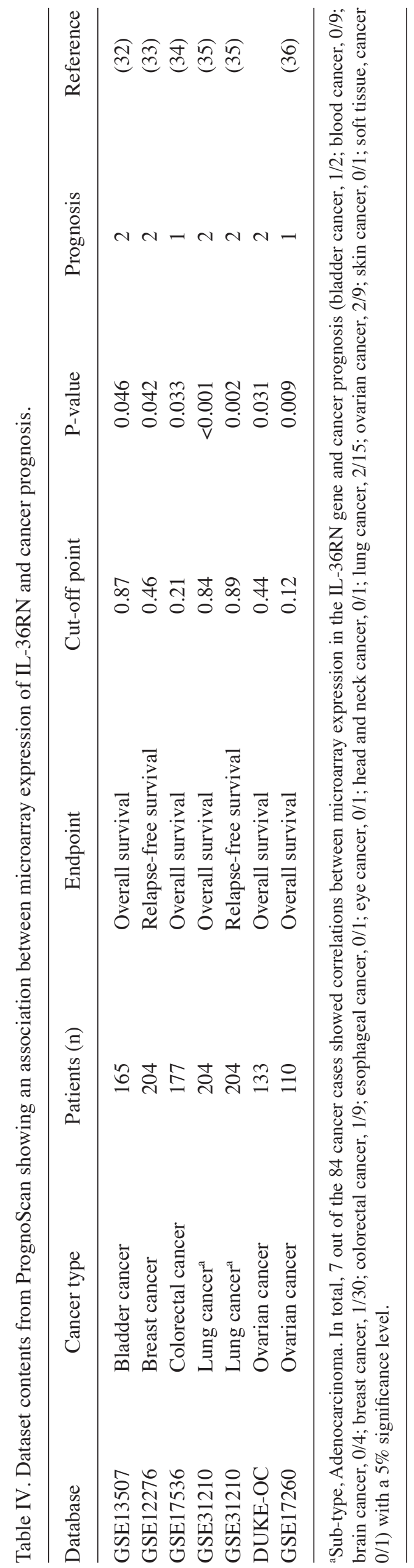

ders (18-20,31), which indicates that changes in IL-36RN SNPs truly contribute to physiological and pathological functions of IL-36Ra. However, another reported IL-36RN mutation in the intron region, rs148755083, which causes GPP (31), was not included in the present study; therefore, further investigation is required to reveal the effects of the other SNPs on the links between IL-36RN and diseases.

In the present study, assessment of the prognostic value of IL-36RN in cancer using the PrognoScan database revealed that IL-36RN is expressed in various cancer types including bladder (32), breast (33), colorectal (34), lung (35) and ovarian cancer (36). In 7 out of 84 cancer cases, IL-36RN was identified as a promising prognostic factor. Furthermore, IL-36RN expression varied among different types of cancer and the prognostic value varied within entries of different databases for the same cancer type. These results suggested that IL-36RN may have multiple roles in cancer development. In addition, 31 somatic mutations of IL-36RN in cancer tissues were identified in the present study. Thus, additional study is required to confirm the preliminary findings of the present study, which indicated that IL-36RN takes part in cancer development, and to assess the underlying mechanisms.

The IL-36RN gene was identified to bind with the AP-1, $\mathrm{c}-\mathrm{Fos}, \mathrm{c}-\mathrm{Jun}$, and NF- $\mathrm{KB}$ regulatory transcription factors in the upstream (promoter) region. Transcription factor AP-1 regulates a broad range of genes involved in cell cycle and inflammation. It mediates the anti-apoptotic response to hypoxic conditions and contributes to resistance to chemo- and radiotherapy in colon cancer cells (37), while it influences pivotal regulators of cell proliferation, migration and survival involved in melanoma progression (38) as well as in the carcinogenesis of the respiratory epithelium (39). c-Fos has been found to be associated with lipid- and phospholipid synthesis in several cell types (40) and activates biogenesis in certain types of tumor cell to support tumor growth $(41,42)$. c-Jun is a critical transcription factor involved in major cell-biological activities, including cell proliferation, apoptosis, angiogenesis and invasiveness by specific regulation of epidermal growth factor receptor, keratinocyte growth factor, cyclin D1, p53, proliferin and CD44 (43-46). NF- $\kappa \mathrm{B}$ is known to be the key regulator of apoptosis and controlled cell suicide by means of controlling pro-apoptotic and anti-apoptotic genes (47-50). NF- $\mathrm{kB}$ exacerbates inflammation-induced cancer types, while it suppresses chemically induced skin and liver cancers (51-53), which suggests that NF- $\mathrm{KB}$ has a dual role in cancer. These transcription factors associated with tumorigenesis may represent a link between IL-36RN and tumorigenesis or cancer progression.

In conclusion, the present study investigated IL-36RN in various species and types of cancer at the gene and protein levels, and the results demonstrated that IL-36RN may have an important role in cancer progression through tumor-associated transcription factors and signaling pathways, but this hypothesis requires further investigation.

\section{Acknowledgements}

The present study was supported by the National Natural Science Foundation of China (no. 81072400), the Research Fund for the Doctoral Program of Higher Education of China (no. 20130142110066), the Scientific Research Foundation 
of Hubei Health Department (no. JX5B54), the Natural Science Foundation of Hubei province (no. 2009CDB148), the Wuhan Planning Project of Science and Technology (no. 201161038340-01) and the Independent Innovation Research Foundation of Huazhong University of Science and Technology (no. 2011JC016).

\section{References}

1. Sims JE, Nicklin MJ, Bazan JF, Barton JL, Busfield SJ, Ford JE, Kastelein RA, Kumar S, Lin H, Mulero JJ, et al: A new nomenclature for IL-1-family genes. Trends Immunol 22: 536-537, 2001.

2. Dinarello C, Arend W, Sims J, Smith D, Blumberg H, O'Neill L, Goldbach-Mansky R, Pizarro T, Hoffman H, Bufler P, et al: IL-1 family nomenclature. Nat Immunol 11: 973, 2010.

3. Sharaf N, Nicklin MJ and di Giovine FS: Long-range DNA interactions at the IL-1/IL-36/IL-37 gene cluster (2q13) are induced by activation of monocytes. Cytokine 68: 16-22, 2014.

4. Mulero JJ, Pace AM, Nelken ST, Loeb DB, Correa TR, Drmanac R and Ford JE: IL1HY1: A novel interleukin-1 receptor antagonist gene. Biochem Biophys Res Commun 263: 702-706, 1999.

5. Towne JE, Renshaw BR, Douangpanya J, Lipsky BP, Shen M, Gabel CA and Sims JE: Interleukin-36 (IL-36) ligands require processing for full agonist (IL-36 $\alpha$, IL-36 $\beta$ and IL-36 $\gamma$ ) or antagonist (IL-36Ra) activity. J Biol Chem 286: 42594-42602, 2011.

6. Costelloe C, Watson M, Murphy A, McQuillan K, Loscher C, Armstrong ME, Garlanda C, Mantovani A, O'Neill LA, Mills KH and Lynch MA: IL-1F5 mediates anti-inflammatory activity in the brain through induction of IL-4 following interaction with SIGIRR/TIR8. J Neurochem 105: 1960-1969, 2008

7. Gresnigt MS and van de Veerdonk FL: Biology of IL-36 cytokines and their role in disease. Semin Immunol 25 : 458-465, 2013

8. Chen H, Wang Y, Bai C and Wang X: Alterations of plasma inflammatory biomarkers in the healthy and chronic obstructive pulmonary disease patients with or without acute exacerbation. J Proteomics 75: 2835-2843, 2012.

9. Ramadas RA, Li X, Shubitowski DM, Samineni S, Wills-Karp M and Ewart SL: IL-1 Receptor antagonist as a positional candidate gene in a murine model of allergic asthma. Immunogenetics 58: 851-855, 2006.

10. van Asseldonk EJ, Stienstra R, Koenen TB, van Tits LJ, Joosten LA, Tack CJ and Netea MG: The effect of the interleukin-1 cytokine family members IL-1F6 and IL-1F8 on adipocyte differentiation. Obesity (Silver Spring) 18: 2234-2236, 2010.

11. Kim TJ, Kim TH, Lee HJ, Peddle L, Rahman P, Hu P, Greenwood CM and Inman RD: Interleukin 1 polymorphisms in patients with ankylosing spondylitis in Korea. J Rheumatol 35 1603-1608, 2008.

12. Frey S, Derer A, Messbacher ME, Baeten DL, Bugatti S, Montecucco C, Schett G and Hueber AJ: The novel cytokine interleukin-36 $\alpha$ is expressed in psoriatic and rheumatoid arthritis synovium. Ann Rheum Dis 72: 1569-1574, 2013.

13. Mattii M, Ayala F, Balato N, Filotico R, Lembo S, Schiattarella M, Patruno C, Marone G and Balato A: The balance between pro-and anti-inflammatory cytokines is crucial in human allergic contact dermatitis pathogenesis: The role of IL-1 family members. Exp Dermatol 22: 813-819, 2013.

14. Heinemann A, He Y, Zimina E, Boerries M, Busch H, Chmel N, Kurz T, Bruckner-Tuderman L and Has C: Induction of phenotype modifying cytokines by FERMT1 mutations. Hum Mutat 32: 397-406, 2011.

15. Karumbaiah L, Norman SE, Rajan NB, Anand S, Saxena T, Betancur M, Patkar R and Bellamkonda RV: The upregulation of specific interleukin (IL) receptor antagonists and paradoxical enhancement of neuronal apoptosis due to electrode induced strain and brain micromotion. Biomaterials 33: 5983-5996, 2012.

16. Towne JE and Sims JE: IL-36 in psoriasis. Curr Opin Pharmacol 12: 486-490, 2012.

17. Marrakchi S, Guigue P, Renshaw BR, Puel A, Pei XY, Fraitag S, Zribi J, Bal E, Cluzeau C, Chrabieh M, et al: Interleukin-36-receptor antagonist deficiency and generalized pustular psoriasis. N Engl J Med 365: 620-628, 2011.
18. Sugiura K, Takeichi T, Kono M, Ogawa Y, Shimoyama Y, Muro Y and Akiyama M: A novel IL36RN/IL1F5 homozygous nonsense mutation, p.Arg10X, in a Japanese patient with adult-onset generalized pustular psoriasis. Br J Dermatol 167: 699-701, 2012.

19. Onoufriadis A, Simpson MA, Pink AE, Di Meglio P, Smith CH, Pullabhatla V, Knight J, Spain SL, Nestle FO, Burden AD, et al: Mutations in IL36RN/IL1F5 are associated with the severe episodic inflammatory skin disease known as generalized pustular psoriasis. Am J Hum Genet 89: 432-437, 2011.

20. Kanazawa N, Nakamura T, Mikita N and Furukawa F: Novel IL36RN mutation in a Japanese case of early onset generalized pustular psoriasis. J Dermatol 40: 749-751, 2013.

21. Kumar S, Nei M, Dudley J and Tamura K: MEGA: A biologist-centric software for evolutionary analysis of DNA and protein sequences. Brief Bioinform 9: 299-306, 2008.

22. Yang Z, Nielsen R, Goldman $N$ and Pedersen AM: Codon-substitution models for heterogeneous selection pressure at amino acid sites. Genetics 155: 431-449, 2000.

23. Yang Z: PAML 4: Phylogenetic analysis by maximum likelihood. Mol Biol Evol 24: 1586-1591, 2007.

24. Wang B, Chen K, Xu W, Chen D, Tang W and Xia TS: Integrative genomic analyses of secreted protein acidic and rich in cysteine and its role in cancer prediction. Mol Med Rep 10: 1461-1468, 2014.

25. Kolker E, Higdon R, Morgan P, Sedensky M, Welch D, Bauman A, Stewart E, Haynes W, Broomall W and Kolker N: SPIRE: Systematic protein investigative research environment. J Proteomics 75: 122-126, 2011.

26. Kolker E, Higdon R, Haynes W, Welch D, Broomall W, Lancet D, Stanberry L and Kolker N: MOPED: Model organism protein expression database. Nucleic Acids Res 40: D1093-D1099, 2012.

27. Wang B, Xu W, Tan M, Xiao Y, Yang H and Xia TS: Integrative genomic analyses of a novel cytokine, interleukin-34 and its potential role in cancer prediction. Int J Mol Med 35: 92-102, 2015.

28. Wang M, Wei X, Shi L, Chen B, Zhao G and Yang H: Integrative genomic analyses of the histamine $\mathrm{H} 1$ receptor and its role in cancer prediction. Int J Mol Med 33: 1019-1026, 2014.

29. Forbes SA, Bindal N, Bamford S, Cole C, Kok CY, Beare D, Jia M, Shepherd R, Leung K, Menzies A, et al: COSMIC: Mining complete cancer genomes in the catalogue of somatic mutations in cancer. Nucleic Acids Res 39: D945-D950, 2011.

30. Mizuno H, Kitada K, Nakai K and Sarai A: PrognoScan: A new database for meta-analysis of the prognostic value of genes. BMC Med Genomics 2: 18, 2009.

31. Sugiura K, Takemoto A, Yamaguchi M, Takahashi H, Shoda Y, Mitsuma T, Tsuda K, Nishida E, Togawa Y, Nakajima K, et al: The majority of generalized pustular psoriasis without psoriasis vulgaris is caused by deficiency of interleukin-36 receptor antagonist. J Invest Dermatol 133: 2514-2521, 2013.

32. Kim WJ, Kim EJ, Kim SK, Kim YJ, Ha YS, Jeong P, Kim MJ, Yun SJ, Lee KM, Moon SK, et al: Predictive value of progression-related gene classifier in primary non-muscle invasive bladder cancer. Mol Cancer 9: 3, 2010.

33. Bos PD, Zhang XH, Nadal C, Shu W, Gomis RR, Nguyen DX, Minn AJ, van de Vijver MJ, Gerald WL, Foekens JA and Massagué $\mathrm{J}$ : Genes that mediate breast cancer metastasis to the brain. Nature 459: 1005-1009, 2009.

34. Smith JJ, Deane NG, Wu F, Merchant NB, Zhang B, Jiang A, Lu P, Johnson JC, Schmidt C, Bailey CE, et al: Experimentally derived metastasis gene expression profile predicts recurrence and death in patients with colon cancer. Gastroenterology 138: 958-968, 2010

35. Okayama H, Kohno T, Ishii Y, Shimada Y, Shiraishi K, Iwakawa R, Furuta K, Tsuta K, Shibata T, Yamamoto S, et al: Identification of genes upregulated in ALK-positive and EGFR/KRAS/ALK-negative lung adenocarcinomas. Cancer Res 72: 100-111, 2012.

36. Yoshihara K, Tajima A, Yahata T, Kodama S, Fujiwara H, Suzuki M, Onishi Y, Hatae M, Sueyoshi K, Fujiwara H, et al: Gene expression profile for predicting survival in advanced-stage serous ovarian cancer across two independent datasets. PLoS One 5: e9615, 2010.

37. Shaulian E and Karin M: AP-1 as a regulator of cell life and death. Nat Cell Biol 4: E131-E136, 2002.

38. Kappelmann M, Bosserhoff A and Kuphal S: AP-1/c-Jun transcription factors: Regulation and function in malignant melanoma. Eur J Cell Biol 93: 76-81, 2014. 
39. Karamouzis MV, Konstantinopoulos PA and Papavassiliou AG: The activator protein-1 transcription factor in respiratory epithelium carcinogenesis. Mol Cancer Res 5: 109-120, 2007.

40. Caputto BL, Cardozo Gizzi AM and Gil GA: C-Fos: an AP-1 transcription factor with an additional cytoplasmic, non-genomic lipid synthesis activation capacity. Biochim Biophys Acta 1841: 1241-1246, 2014.

41. Milde-Langosch K: The Fos family of transcription factors and their role in tumourigenesis. Eur J Cancer 41: 2449-2461, 2005.

42. Motrich RD, Castro GM and Caputto BL: Old players with a newly defined function: Fra-1 and c-Fos support growth of human malignant breast tumors by activating membrane biogenesis at the cytoplasm. PLoS One 8: e53211, 2013.

43. Bakiri L, Lallemand D, Bossy-Wetzel E and Yaniv M: Cell cycle-dependent variations in c-Jun and JunB phosphorylation: A role in the control of cyclin D1 expression. EMBO J 19: 2056-2068, 2000.

44. Zenz R, Scheuch H, Martin P, Frank C, Eferl R, Kenner L, Sibilia M and Wagner EF: C-Jun regulates eyelid closure and skin tumor development through EGFR signaling. Dev Cell 4: 879-889, 2003.

45. Mils V,Piette J, Barette C, Veyrune J, Tesnière A, Escot C, Guilhou JJ and Basset-Séguin $\mathrm{N}$ : The proto-oncogene c-fos increases the sensitivity of keratinocytes to apoptosis. Oncogene 14: 1555-1561, 1997.
46. Schreiber M, Kolbus A, Piu F, Szabowski kA, Möhle-Steinlein U, Tian J, Karin M, Angel P and Wagner EF: Control of cell cycle progression by c-Jun is p53 dependent. Genes Dev 13: 607-619, 1999.

47. Chen $\mathrm{F}$ and Castranova V: Nuclear factor-kappaB, an unappreciated tumor suppressor. Cancer Res 67: 11093-11098, 2007.

48. Horst D, Budczies J, Brabletz T, Kirchner T and Hlubek F: Invasion associated up-regulation of nuclear factor kappaB target genes in colorectal cancer. Cancer 115: 4946-4958, 2009.

49. Zubair A and Frieri M: Role of nuclear factor-kB in breast and colorectal cancer. Curr Allergy Asthma Rep 13: 44-49, 2013.

50. Yu LL, Yu HG, Yu JP, Luo HS, Xu XM and Li JH: Nuclear factor-kappaB p65 (RelA) transcription factor is constitutively activated in human colorectal carcinoma tissue. World J Gastroenterol 10: 3255-3260, 2004.

51. Vainer GW, Pikarsky E and Ben-Neriah Y: Contradictory functions of NF-kappaB in liver physiology and cancer. Cancer Lett 267: 182-188, 2008.

52. Arsura $M$ and Cavin LG: Nuclear factor-kappaB and liver carcinogenesis. Cancer Lett 229: 157-169, 2005.

53. Karin M: Nuclear factor-kappaB in cancer development and progression. Nature 441: 431-436, 2006. 